\title{
Gender differences in task-based performance of EFL students
}

\begin{abstract}
Although various studies have been conducted to examine gender difference regarding different aspects of language learning, the results reveal inconsistencies. This study examined the difference between the performances of male and female EFL learners on three taskbased activities. A random sample of 120 participants in an Iranian English school (in Mashhad) was drawn from the pre-intermediate level (60 male and 60 female). Students' performances of three task types were evaluated using a validated rating checklist with a reliability of 0.87 . The results proved that there was no significant difference between the task-based performances of male and female students suggesting that the gender imposes no difference on EFL learners' performances of task-based activities.
\end{abstract}

Keyword: Gender; Information-gap; Opinion-gap; Reasoning-gap; Task-based language teaching 